University of Nebraska - Lincoln

DigitalCommons@University of Nebraska - Lincoln

U.S. Department of Veterans Affairs Staff

Publications

U.S. Department of Veterans Affairs

2006

\title{
Neurocognitive and social cognitive correlates of formal thought disorder in schizophrenia patients
}

\author{
Kenneth L. Subotnik \\ University of California - Los Angeles, ksubotnik@mednet.ucla.edu \\ Keith H. Nuechterlein \\ University of California - Los Angeles, keithn@ucla.edu \\ Michael F. Green \\ University of California - Los Angeles \\ William P. Horan \\ University of California - Los Angeles, horan@ucla.edu \\ Tasha M. Nienow \\ University of California - Los Angeles \\ See next page for additional authors
}

Follow this and additional works at: https://digitalcommons.unl.edu/veterans

Subotnik, Kenneth L.; Nuechterlein, Keith H.; Green, Michael F.; Horan, William P.; Nienow, Tasha M.; Ventura, Joseph; and Nguyen, Annie T., "Neurocognitive and social cognitive correlates of formal thought disorder in schizophrenia patients" (2006). U.S. Department of Veterans Affairs Staff Publications. 76. https://digitalcommons.unl.edu/veterans/76

This Article is brought to you for free and open access by the U.S. Department of Veterans Affairs at DigitalCommons@University of Nebraska - Lincoln. It has been accepted for inclusion in U.S. Department of Veterans Affairs Staff Publications by an authorized administrator of DigitalCommons@University of Nebraska - Lincoln. 
Authors

Kenneth L. Subotnik, Keith H. Nuechterlein, Michael F. Green, William P. Horan, Tasha M. Nienow, Joseph Ventura, and Annie T. Nguyen 


\title{
Neurocognitive and social cognitive correlates of formal thought disorder in schizophrenia patients
}

\author{
Kenneth L. Subotnik $^{\mathrm{a}, *}$, Keith H. Nuechterlein ${ }^{\mathrm{a}, \mathrm{b}}$, Michael F. Green ${ }^{\mathrm{a}, \mathrm{c}}$, \\ William P. Horan ${ }^{\text {a }}$, Tasha M. Nienow ${ }^{\text {a }}$, Joseph Ventura ${ }^{\text {a }}$, Annie T. Nguyen ${ }^{\text {a }}$ \\ ${ }^{a}$ Department of Psychiatry and Biobehavioral Sciences, University of California, Los Angeles, 300 UCLA Medical Plaza, \\ Room 2240, Los Angeles, CA 90095-6968, USA \\ b Department of Psychology, University of California, Los Angeles, USA \\ ${ }^{c}$ Veterans Affairs Greater Los Angeles Healthcare System, USA \\ Received 7 February 2006; accepted 3 March 2006 \\ Available online 19 April 2006
}

\begin{abstract}
The neurocognitive and social cognitive correlates of two types of formal thought disorder (i.e., bizarre-idiosyncratic and concrete thinking) were examined in 47 stable outpatients with schizophrenia. Both types of thinking disturbance were related to impairments in verbal learning, intrusions in verbal memory, immediate auditory memory, sustained attention, and social schema knowledge. Distractibility during an immediate memory task was associated with more frequent bizarre verbalizations but not concreteness. Impaired verbal learning rate and intrusions in verbal memory independently contributed to the prediction of bizarre responses, whereas intrusions in verbal memory and impaired immediate memory independently contributed to concrete thinking. This pattern of findings is consistent with the view that neurocognitive and, possibly, social cognitive deficits underlie these two aspects of formal thinking disturbance in schizophrenia.
\end{abstract}

(C) 2006 Elsevier B.V. All rights reserved.

Keywords: Schizophrenia; Proverbs; Neurocognition; Social cognition; Formal thought disorder; Concrete thinking

\section{Introduction}

Formal thought disorder is a multifaceted construct that encompasses a diverse set of thinking disturbances, including loose and indirect associations, overly abstract or concrete responses, illogicality, inappropriate intrusion of personal material, and unusual

\footnotetext{
* Corresponding author.

E-mail address: ksubotnik@mednet.ucla.edu (K.L. Subotnik).
}

word usage (Holzman et al., 1986). Thought disorder has been considered to be a core feature of schizophrenia (Bleuler, 1950) and has been described as either a positive symptom (Andreasen and Olsen, 1982) or as part of the disorganization syndrome (Liddle, 1987). Longitudinal studies have found that the severity of thought disorder in schizophrenia is moderately stable typically (Adler and Harrow, 1974; Asarnow and MacCrimmon, 1982; Docherty et al., 2003) but becomes exacerbated during acute episodes

0920-9964/\$ - see front matter (C) 2006 Elsevier B.V. All rights reserved. doi:10.1016/j.schres.2006.03.007 
of illness. However, even in relatively stable outpatients, the frequency of thinking disturbance has been found to be greater among patients with schizophrenia than nonpsychiatric controls (Sponheim et al., 2003). Formal thought disorder appears to lessen in geriatric patients with chronic schizophrenia, but this might be an artifact of decreased verbal productivity in older patients (Bowie et al., 2005). This pattern of findings suggests that formal thought disorder reflects, in part, state-like exacerbations in illness but also might be associated with more stable underlying neurocognitive impairments. This conclusion is supported by longitudinal studies that have found the relationship between thought disorder and discrete neurocognitive deficits to be stronger during periods of stabilization than during acute episodes (Asarnow and MacCrimmon, 1982; Nuechterlein et al., 1986; Pandurangi et al., 1994). Neuropsychologists and experimental psychopathologists have frequently assessed the quality of thinking using proverb interpretation tasks (Lezak, 1995). Accurate interpretation of proverbs requires the individual to report the consensually recognized meaning from the symbols in the proverb. Bizarre-idiosyncratic thinking is defined as a unique response that often deviates from social norms and that may contain confused, contradictory, or illogical verbalizations. Consequently, idiosyncratic responses are typically inappropriate or inadequate in relation to the presented stimulus and are often difficult for others to empathize with or understand (Marengo et al., 1986). Assessment of thought disturbance on proverb interpretation tasks involves scoring the quality of participants' responses with standardized dimensional measures of bizarre-idiosyncratic and concrete thinking. Patients with schizophrenia perform more poorly than nonpsychiatric controls on proverb interpretation tasks, with their responses containing more idiosyncratic and concrete thinking disturbances (Carter, 1986; Sponheim et al., 2003). While patients with schizophrenia have been found to make both idiosyncratic and concrete thinking errors, these two types of thinking disturbances have been found to be only weakly to moderately related (Craig, 1973; Silverstein et al., 1993; Sponheim et al., 2003). A third construct based on proverb tasks, correct abstraction, is related to concrete thinking, but involves not only the ability to abstract beyond the concrete elements of the proverb but also to correctly identify the consensually derived meaning of the proverb.

Despite the clinical significance and stability of thought disorder, relatively little is known about its neurocognitive underpinnings (Kerns and Berenbaum, 2002). Formal thought disorder has been found to relate to impairments in attention (Docherty and Gordinier, 1999; Harvey et al., 1998; Moser et al., 2001; Nuechterlein et al., 1986; Silverstein et al., 1991; Sowell et al., 2000), memory (Harvey et al., 1998; Nestor et al., 1998; Serper et al., 1990), and executive functions (Barrera et al., 2005; Nestor et al., 1998). However, few studies have examined multiple neurocognitive domains as correlates of formal thought disorder within the same sample. In addition, few, if any, studies have included measures of social cognition. Furthermore, the specific contributions of these measures beyond their correlations with general intellectual ability have not been adequately studied.

Prior studies of the neurocognitive contributors to bizarre-idiosyncratic thinking have produced inconsistent results. In their study of the determinants of idiosyncratic thinking, Harrow et al. (1989) noted that idiosyncratic responses are often not recognized as such by the speaker and can be reduced when the speaker is directed to focus on the quality of the response. These observations led them to hypothesize that bizarre-idiosyncratic thinking might, at least in part, result from impaired access to knowledge of what behavior is socially or contextually appropriate for a situation and from a reduced ability to monitor their verbalizations. In one of the first empirical studies designed to identify neurocognitive correlates of bizarre-idiosyncratic thinking Silverstein et al. (1993) used a battery of linguistic, complex attentional, and intellectual measures and found that $25 \%$ of the variance in idiosyncratic thinking could be explained by estimated intellectual ability and arithmetic performance. Similarly, Carpenter and Chapman (1982) reported a moderate relationship between bizarreidiosyncratic thinking and intellectual ability. However, Sponheim et al. (2003) failed to find significant relationships between idiosyncratic thinking and intellectual ability, memory, or executive abilities.

Contradictory findings have also been found with regard to the correlates of concrete thinking. Silverstein et al. (1993) found that indices of left and right cerebral lateralization from the Luria Nebraska Neu- 
ropsychological Battery explained only $11 \%$ and $14 \%$ of the variance in concrete thinking, respectively, and they failed to identify any independent neurocognitive predictors. In contrast, Sponheim et al. (2003) reported that $59 \%$ of the variance in concreteness could be explained by estimated intellectual ability and impairment in complex attention, visual memory, and planning. Other investigators also have found moderate to strong inverse relationships between verbal intellectual ability and concreteness, but these studies did not assess more specific neurocognitive deficits (Hertler et al., 1978; Shimkunas et al., 1966). In contrast to the varying results for idiosyncratic and concrete thinking, a moderate to strong positive relationship has consistently been found between correct abstraction on proverbs and intellectual ability (Carpenter and Chapman, 1982; Harrow et al., 1974; Shimkunas et al., 1966). These studies were limited to the assessment of intellectual ability, and to our knowledge, associations with more specific neurocognitive abilities have not been examined.

The goals of this study are: 1) to identify the neurocognitive and social cognitive correlates of these measures of formal thought disorder; 2) to identify which cognitive correlates account for unique variance in formal thought disorder; and 3) to examine the extent to which these neurocognitive and social cognitive correlates account for variance in formal thought disorder after accounting for general verbal ability. We focused on bizarre-idiosyncratic thinking rated from proverbs as a measure of formal thought disorder. Although the Bizarre-Idiosyncratic Thinking Rating System is less comprehensive than the Thought, Language, and Communication scale (TLC) (Andreasen, 1986), we used the BizarreIdiosyncratic Thinking Rating System because we have previously demonstrated that it is more sensitive to subtle thought disorder than typical clinical ratings based on conversational speech in the context of a psychiatric interview, such as the conceptual disorganization item from the Brief Psychiatric Rating Scale (Subotnik et al., 2003). The neurocognitive measures were selected from a battery that assessed simple and complex attention, working memory, and verbal learning. In addition, a measure of social schema knowledge was included because Harrow et al. (1989) hypothesized that impaired access to socially relevant information might contribute to bizarre-idiosyncratic thinking. The Social Feature Recognition Test (SFRT) (Corrigan and Green, 1993) is an instrument that quantifies the extent to which an individual has knowledge of the features (actions, goals, etc.) of social situations. Performance on the SFRT was expected to contribute independently to bizarreidiosyncratic thinking. We examined two aspects of formal thought disorder-bizarre-idiosyncratic and concrete responses to proverbs-and a related construct, correct abstraction of proverbs, in order to examine their differing patterns of relationships to the neurocognitive and social neurocognitive measures.

\section{Methods}

\subsection{Participants}

Participants were receiving outpatient psychiatric treatment at the UCLA Aftercare Research Program and were either current or past participants in one of three longitudinal studies of the early phase of schizophrenia (Developmental Processes in Schizophrenic Disorders Project; P.I., Keith H. Nuechterlein, PhD). Full details of entry criteria for the Developmental Processes project are available in Nuechterlein et al. (1992). All participants met Research Diagnostic Criteria (Spitzer et al., 1978) for either schizophrenic disorder or schizoaffective disorder, mainly schizophrenic. Classification by the Diagnostic and Statistical Manual of Mental Disorders, 4th ed. (American Psychiatric Association, 1994) was as follows: Schizophrenia $(n=31)$, schizophreniform $(n=9)$, schizoaffective disorder $(n=6)$, or psychotic disorder not otherwise specified $(n=1)$. The participants included 35 males and 12 females, and had a mean age of 28.6 years (S.D. $=6.4)$. The mean age of illness onset was 23.6 years (S.D. $=5.6$ ), with a mean duration of total illness, including prodromal symptoms, of 5.5 years $($ S.D. =4.4). All were fluent in English. The participants' parents had a mean education level of 13.0 years (S.D. $=2.7)$. The total score on the 24-item Brief Psychiatric Rating Scale (BPRS)(Ventura et al., 1993) at the time of the proverb task assessment was 39.7 (S.D.=12.6). All participants were presented with oral and written information about the research procedures involved in the study, and they gave written informed consent. 


\subsection{Measures}

\subsubsection{Formal thought disorder}

\subsubsection{Bizarre-Idiosyncratic Thinking Rating System} (BIZ) (Marengo et al., 1986). Responses to all three sets (of 12 proverbs each) of the Gorham Proverbs Test (Gorham, 1956) were used as speech samples from which to rate bizarre-idiosyncratic thinking. The proverbs were standard, common proverbs (e.g., "Strike while the iron is hot", "When the cat's away the mice will play"), albeit some are outdated and infrequently used (e.g., "There's many a slip twixt cup and the lip"). Proverbs were read to participants and they were asked to explain the meaning of the saying. The responses were not scored according to the Gorham (1956) criteria, but were used as speech samples for rating bizarre-idiosyncratic thinking following the procedures of Marengo et al. (1986). The overall rating of bizarre-idiosyncratic thinking was used as the primary measure of bizarre responding. Each proverb response is rated on the following scale: $0=$ absent; $0.5=$ mild or minimal bizarre qualities; $1.0=$ moderate or clear evidence of bizarre thinking, 3.0 $=$ very severe bizarre responding. Interrater reliability was established based on 10 proverb protocols between our staff raters and criterion ratings provided by the scale authors (average intraclass $r=.83$, range .73 to .93 .).

On average, participants did not provide responses (e.g., "I don't know") to $21.4 \%$ of the proverbs administered. Participants might not provide a response to a proverb for varied reasons, such as unfamiliarity with the proverb (perhaps because it is outdated and infrequently used), low intelligence, low motivation, low self-esteem, as well as formal thought disorder. Because we could not assume that not responding was attributable to formal thought disorder, we excluded instances of no response to a proverb. The sum of the thought disorder ratings for each participant was divided by the total number of responses given. The mean BIZ score on items for which a ratable response was given was 0.2 (S.D. $=0.3)$

\subsubsection{Abstract/Concrete Rating System (Marengo et} al., 1986). The responses to the Gorham Proverbs Test were also used to rate concrete thinking and correct abstraction. Concreteness and abstraction were coded according to the definitions and procedures provided by Marengo et al. (1986). An answer is scored as concrete when a respondent fails to translate the symbols or ideas presented in the proverb into a more generalizable interpretation and instead either explains, reacts to, or expands upon the original words of the proverb. Responses are scored as abstract when the proverb's key symbols have been decoded into more global concepts or generalizations regardless of the correctness of the translation. Abstract responses are then evaluated for correctness. If the respondent's answer captures the essential, consensually derived meaning of the proverb, it is scored as abstractcorrect. Because we could not assume that nonresponse to proverb was attributable to concrete thinking, we computed mean summary scores by dividing by the number of ratable responses. Note that the categories of concrete and abstract are mutually exclusive. To eliminate redundancy with the concrete ratings, the correlates of abstract responses will not be reported. Ratings on this scale were made by two staff raters whose ratings yielded an intraclass correlation was .86 for Concrete responses and .82 for AbstractCorrect responses. For ratable responses to the proverbs, the mean concrete responding score $(0=a b-$ stract, $1=$ concrete) was 0.35 (S.D. $=.23$ ), and the mean correct abstraction score was 0.33 (S.D. $=.20$ ).

\subsubsection{Neurocognition and social cognition}

\subsubsection{Digit Span Distractibility Test (DSDT) (Olt-} manns and Neale, 1975). In this test of immediate or working auditory memory and distractibility, participants listen to and repeat strings of digits presented via audiotape by a female voice under nondistraction and distraction conditions. In the distraction condition, irrelevant digits were presented by a male voice between the relevant digits. Immediate auditory memory was measured as recall for the long (6 to 8) digit series during the nondistraction and the distraction conditions, each of which involves seven items (Oltmanns, 1978). Distractibility was computed as the difference between recall under nondistraction and distraction conditions.

2.2.2.2. California Verbal Learning Test (CVLT) (Delis et al., 1983). The CVLT is a test of verbal 
learning and episodic memory. Participants were read lists of 16 semantically related words and asked to recall as many of the words as possible under various conditions of delay ( 0 vs. $20 \mathrm{~min}$ ), type of recall (free vs. cued/recognition), and retroactive inhibition (the interpolation of another list). Indices of verbal learning and attentional disturbance derived from the CVLT examined here were: total recall on trials $1-5$, learning slope, and intrusions.

\subsubsection{Degraded Stimulus Continuous Performance} Test (DS-CPT) (Nuechterlein, 1983). Sustained, focused attention involving perceptual analysis and discrimination processes was measured with a computerized version of the DS-CPT (Nuechterlein and Asarnow, 1999a). This task required the participant to detect occurrences of " 0 " during an 8-min period of presentation of highly blurred single digits, $33 \mathrm{~ms}$ each and 1/s. A black/white reversal of a random $40 \%$ of pixels was used to produce degradation of the stimulus as well as the background to create visual noise. The proportion of targets was 0.25 . A measure of signal/noise discrimination, $d^{\prime}$, was the primary performance variable.

\subsubsection{Memory Load Continuous Performance Test} (3-7 CPT) (Nuechterlein et al., 1986). This refinement of the original A-X CPT (Rosvold et al., 1956) measures focused, sustained attention under immediate memory load conditions. Specifically, the participant was asked to press a button each time that a " 3 " was followed by a " 7 " within a quasirandom series of single, clearly focused numeral stimuli presented for $33 \mathrm{~ms}$ each at a rate of $1 / \mathrm{s}$. In this computerized version, (Nuechterlein and Asarnow, 1999b) 640 stimuli were presented, $25 \%$ of which were 3-7 sequences $(12.5 \%$ were 7 's that required a response). The primary performance measure was again $d^{\prime}$.

\subsubsection{The Wechsler Adult Intelligence Scale-Revised} Vocabulary Subtest. The WAIS-R Vocabulary subtest was administered using standard procedures (Wechsler, 1981). The scaled score was used as an index of general verbal ability (Lezak, 1995).

2.2.2.6. The Situational Feature Recognition Test (SFRT) (Corrigan and Green, 1993). The SFRT assesses participants' sensitivity to abstract and concrete features of social situations. The primary use of the test is to assess social representation deficits in schizophrenic patients (Corrigan et al., 1992). The test assesses participants' knowledge about four different social situations: eating at a restaurant, attending an appointment with a doctor, being a patient at a psychiatric hospital, and attending an opera. For each social situation, participants were presented with a printed list of 14 actions, 14 roles, 14 rules, and 14 goals (each containing 6 targets and 8 distracters). Participants were instructed to circle the actions, roles, rules, and goals that would be appropriate for each type of social situation. Following the procedures described by Corrigan and Green (1993) a discrimination index, $A^{\prime}$, was computed for all ratings of actions, roles, rules, and goals. Mean $A^{\prime}$ scores were computed for each of the qualities across the four types of social situations. The scores tended to be negatively skewed, so an arcsine of the square root transformation was applied.

\subsubsection{Psychiatric symptom assessment}

2.2.3.1. Brief Psychiatric Rating Scale (BPRS) (Ventura et al., 1993). Severity of psychiatric symptoms during the 2-week period prior to study participation was assessed using the expanded version of the Brief Psychiatric Rating Scale. Severity was rated on a 7 point scale $(1=$ not present, $7=$ severe $)$. On average, participants did not have significant formal thought disorder as measured by the BPRS Conceptual Disorganization item (mean rating $=1.4$. S.D. $=1.0$ ) or the Thinking Disturbance factor $(M=1.8$, S.D. $=1.1)$. Only 16 participants were rated a "4" or above on any of the three positive symptom items comprising the Thinking Disturbance factor (BPRS items Unusual Thought Content, Hallucinatory Behavior, and Conceptual Disorganization).

\section{Results}

An initial set of bivariate correlational analyses examined whether the key neurocognitive and social cognitive variables predicted the three indices of proverb interpretation-bizarre-idiosyncratic responses, con- 
crete responses, and abstract correct responses. The descriptive statistics for these variables and the correlational results are described below and summarized in Table 1.

\subsection{Bizarre-idiosyncratic, concrete, and correct abstraction responses to proverbs}

More frequent bizarre responses to the proverbs were associated with more frequent concrete $(r=.63$, $p=.01)$ and with fewer correct abstraction responses $(r=-.36, p=.02)$. As would be expected, the categories of concrete and correct abstraction were inversely correlated $(r=-.75, p=.01)$.

None of the three proverb ratings were significantly associated with the degree of positive psychotic symptoms as measured by the BPRS Thinking
Disturbance factor score. In addition, response bizarreness showed a weak correlation with the BPRS conceptual disorganization item that was not statistically significant $(r=.28, p=.08)$.

\subsection{Verbal learning, working memory}

As shown in Table 1, frequency of bizarre proverb responses was significantly associated with several indices of verbal learning and immediate auditory memory. Most notably, significant relationships were found with rate of verbal learning, word intrusion errors during recall, DSDT immediate auditory memory, and DSDT distractibility. The verbal learning and memory correlates of concrete responding were quite similar. Significant relationships were found with verbal learning rate, intrusion errors, and

Table 1

Neurocognitive and social cognitive correlates of formal thought disorder

\begin{tabular}{|c|c|c|c|c|c|}
\hline Measure & Mean (S.D.) & & Bizarre & Concrete & Correct abstraction \\
\hline \multicolumn{6}{|l|}{ Verbal learning, immediate memory } \\
\hline \multirow[t]{2}{*}{ CVLT recall, trials $1-5$} & \multirow[t]{2}{*}{$44.96(11.26)$} & Pearson correlation & -.39 & -.51 & .24 \\
\hline & & Sig. (2-tailed) & .01 & .00 & .11 \\
\hline \multirow[t]{2}{*}{ CVLT learning slope: raw score } & \multirow[t]{2}{*}{$1.02(.72)$} & Pearson correlation & -.45 & -.21 & -.05 \\
\hline & & Sig. (2-tailed) & .00 & .16 & .73 \\
\hline \multirow[t]{2}{*}{ CVLT total intrusions (free and cued): raw } & \multirow[t]{2}{*}{$4.04(5.86)$} & Pearson correlation & .43 & .61 & -.39 \\
\hline & & Sig. (2-tailed) & .00 & .00 & .01 \\
\hline \multirow[t]{2}{*}{ DSDT: nondistraction condition } & \multirow[t]{2}{*}{$.72(.19)$} & Pearson correlation & -.31 & -.45 & .49 \\
\hline & & Sig. (2-tailed) & .05 & .00 & .00 \\
\hline \multirow{2}{*}{$\begin{array}{l}\text { DSDT: difference between nondistraction } \\
\text { and distraction conditions }\end{array}$} & \multirow[t]{2}{*}{$-.02(.12)$} & Pearson Correlation & .33 & .06 & -.08 \\
\hline & & Sig. (2-tailed) & .04 & 67 & .59 \\
\hline \multicolumn{6}{|c|}{ Sustained focused attention and early perceptual processing } \\
\hline \multirow[t]{2}{*}{ DS-CPT: $d^{\prime}$} & \multirow[t]{2}{*}{$2.24(1.11)$} & Pearson correlation & -.38 & -.51 & .159 \\
\hline & & Sig. (2-tailed) & .06 & .01 & .44 \\
\hline \multirow{2}{*}{ 3-7 CPT: $d^{\prime}$} & \multirow[t]{2}{*}{$3.65(1.04)$} & Pearson correlation & -.40 & -.25 & .33 \\
\hline & & Sig. (2-tailed) & .04 & .20 & .08 \\
\hline \multicolumn{6}{|l|}{ Social Features Recognition Test (SFRT) } \\
\hline \multirow[t]{2}{*}{ SFRT rules } & \multirow[t]{2}{*}{$.91(.06)$} & Pearson correlation & -.35 & -.24 & .19 \\
\hline & & Sig. (2-tailed) & .02 & .11 & .21 \\
\hline \multirow[t]{2}{*}{ SFRT rules } & \multirow[t]{2}{*}{$.93(.03)$} & Pearson correlation & -.02 & -.06 & .20 \\
\hline & & Sig. (2-tailed) & .88 & .68 & .19 \\
\hline \multirow[t]{2}{*}{ SFRT acts } & \multirow[t]{2}{*}{$.93(.03)$} & Pearson correlation & -.21 & -.04 & .12 \\
\hline & & Sig. (2-tailed) & .18 & .80 & .42 \\
\hline \multirow[t]{2}{*}{ SFRT goals } & \multirow[t]{2}{*}{$.92(.04)$} & Pearson correlation & -.26 & -.31 & .23 \\
\hline & & Sig. (2-tailed) & .09 & .04 & .12 \\
\hline \multicolumn{6}{|l|}{ General verbal ability } \\
\hline \multirow{2}{*}{ WAIS-R Vocabulary scaled score } & \multirow[t]{2}{*}{$8.7(3.1)$} & Pearson correlation & -.54 & -.66 & .71 \\
\hline & & Sig. (2-tailed) & .01 & .01 & .01 \\
\hline
\end{tabular}


immediate auditory memory. In contrast, correct abstraction was associated with fewer intrusion errors and better immediate auditory memory.

\subsection{Sustained focused attention and early perceptual processing}

Data for the computerized DS-CPT and 3-7 CPT were available for only 30 participants, 26 of whom also had available ratings on bizarreness of proverb responses. The other study participants had taken a noncomputerized form of these tests that was not comparable, and therefore, not included in this analysis. Bizarre responding was significantly correlated with 3-7 CPT $d^{\prime}$ and showed a tendency in the same direction for DS-CPT $d^{\prime}$. Twenty-nine of the participants with computerized DS-CPT and 3-7 CPT data also had ratings of concreteness and correct abstraction of proverb responses. The proportion of proverbs rated as concrete was significantly associated with DS-CPT $d^{\prime}$, but not with 3-7 CPT $d^{\prime}$.

\subsection{Social schema}

Bizarreness of proverb responses was significantly associated with poorer ability to correctly identify the "rules" of social situations on the SFRT test, and concrete responses were associated with poorer ability to correctly identify the correct "goals." Correct abstraction on proverbs was not significantly associated with SFRT performance. Of note, none of the SFRT categories were significantly associated with the WAIS-R Vocabulary scaled score ( $r$ 's ranged from -.04 to .28 ).

\subsection{WAIS-R Vocabulary subtest}

Higher WAIS-R Vocabulary scores were significantly associated with less bizarre-idiosyncratic proverb responses, fewer concrete responses, and more frequent correctly abstracted proverb responses.

\subsection{Multivariate prediction of responses to proverbs}

To determine which of the different neurocognitive and social cognitive variables made independent contributions to the prediction of anomalous proverb responses, we entered these variables into multiple regression models. Selection of predictors within tests emphasized the strongest bivariate relationship with the proverb score. The measures from the DS-CPT and the 3-7 CPT were not included in any of the multiple regression analyses because comparable data were unavailable for a substantial subset of participants due to the initial use of noncomputerized CPTs.

\subsubsection{Bizarre responses to proverbs}

For bizarre proverb responses, the predictor variables were CVLT learning slope for trials 1 through 5, CVLT total intrusions, DSDT distractibility index, and SFRT rules subscale score. This model accounted for $40 \%$ of the variance in bizarre responding (see Table 2). The CVLT learning slope and intrusion error total made significant independent contributions to the prediction of bizarre responses, while the DSDT distractibility index and SFRT rules subscale score did not.

To examine whether the neurocognitive measures contribute to the prediction of bizarre responding after

Table 2

Multiple regression models for bizarre, concrete, and correct abstraction proverb responses

\begin{tabular}{|c|c|c|c|c|c|c|c|c|c|c|c|c|}
\hline \multirow[b]{3}{*}{ Overall model } & \multicolumn{4}{|c|}{ Bizarre } & \multicolumn{4}{|c|}{ Concrete } & \multicolumn{4}{|c|}{ Correct abstraction } \\
\hline & $R^{2}$ & $d f$ & $B$ & $p$ & $\mathrm{R}^{2}$ & $d f$ & $B$ & $p$ & $\mathrm{R}^{2}$ & $d f$ & $B$ & $p$ \\
\hline & .40 & 4,37 & NA & .001 & .54 & 4,41 & NA & .001 & .31 & 2,43 & NA & .001 \\
\hline CVLT learning trials $1-5$ & & & - & - & & & -.18 & .16 & & & - & - \\
\hline CVLT learning slope $1-5$ & & & -.31 & .04 & & & - & - & & & - & - \\
\hline CVLT intrusions (free and cued) & & & .33 & .02 & & & .44 & .01 & & & -.29 & .03 \\
\hline DSDT nondistraction & & & - & - & & & -.28 & .02 & & & .42 & .003 \\
\hline DSDT distractability index & & & .22 & .10 & & & - & - & & & - & - \\
\hline SFRT rules & & & -.11 & .46 & & & - & - & & & - & - \\
\hline SFRT goals & & & - & - & & & -.16 & .16 & & & - & - \\
\hline
\end{tabular}

$-=$ variable not entered into regression model. 
accounting for prediction by general verbal ability, this analysis was repeated, controlling for WAIS-R Vocabulary level. WAIS-R Vocabulary scaled score was entered in step 1 and explained $29 \%$ of the variance (see Table 3). The remaining predictor variables were entered in step 2 , and the total model accounted for $52 \%$ of the variance in bizarreidiosyncratic thinking (for $R^{2}$ change, $F(4,34)=4.1$, $p=.008)$. It is also noteworthy that the BPRS conceptual disorganization item, which we previously found not to have the same sensitivity to subtle formal thought disorder, was not as well predicted by this model. The model accounted for only $19 \%$ of the variance in the BPRS conceptual disorganization item (27\% with WAIS-R Vocabulary).

\subsubsection{Concrete responses to proverbs}

A separate multiple regression model examined the significant correlates of concrete thinking. The predictor variables for concrete thinking were: CVLT learning trials $1-5$, CVLT total intrusions, DSDT nondistraction condition performance, and SFRT goals subscale. A regression model with these predictors accounted for $54 \%$ of the variance in concrete responding. CVLT intrusions and DSDT immediate recall for nondistraction items independently contributed to the prediction of concrete thinking.

Again, a second regression model was computed with the WAIS-R Vocabulary scaled score entered in step 1 to examine the extent to which the more specific neurocognitive variables predicted thought disorder beyond their relationship with general verbal ability. The WAIS-R Vocabulary scale accounted for $45 \%$ of the variance in concrete thinking (see Table 3 ). With the remaining predictor variables entered in step 2, the total model accounted for $67 \%$ of the variance (for $R^{2}$ change, $F(4,36)=5.8, p=.001$ ).

\subsubsection{Correctly abstracted responses to proverbs}

A multiple regression model to explain the variance in correct abstraction was computed with CVLT total intrusions (free and cued) and DSDT nondistraction condition performance as predictor variables. This regression model accounted for $31 \%$ of the variance in correctly abstracted responding, with both neurocognitive measures independently contributing to the prediction of correct abstraction.

Again, a second multiple regression analysis entered the WAIS-R Vocabulary score in step 1, with the other predictor variables entered in step 2. The WAIS-R Vocabulary score accounted for $53 \%$ of the variance in correct abstraction, and the full model accounted for a total of $57 \%$ of the variance. The neurocognitive variables in step 2 did not add significantly to the overall prediction of correct abstraction (for $R^{2}$ change, $F(2,38)=1.8, p=.18$, for step 2)(see Table 3).

\section{Discussion}

Two aspects of formal thought disorder, bizarreidiosyncratic and concrete thinking, were rated from responses to proverbs in outpatients with schizophrenia. Whereas previous studies have found these

Table 3

Multiple regression models for bizarre, concrete, and correct abstraction proverb responses (including WAIS-R Vocabulary as a predictor)

\begin{tabular}{|c|c|c|c|c|c|c|c|c|c|c|c|c|}
\hline \multirow[b]{3}{*}{ Overall model } & \multicolumn{4}{|c|}{ Bizarre } & \multicolumn{4}{|c|}{ Concrete } & \multicolumn{4}{|c|}{ Correct abstraction } \\
\hline & $R^{2}$ & $d f$ & $B$ & $p$ & $\mathrm{R}^{2}$ & $d f$ & $B$ & $p$ & $\mathrm{R}^{2}$ & $d f$ & $B$ & $p$ \\
\hline & .52 & 5,34 & NA & .001 & .67 & 5,36 & NA & .001 & .57 & 3,38 & NA & .001 \\
\hline WAIS-R Vocabulary scaled score & & & -.46 & .002 & & & -.40 & .002 & & & -.60 & .001 \\
\hline CVLT learning trials $1-5$ & & & - & - & & & -.26 & .03 & & & - & - \\
\hline CVLT learning slope $1-5$ & & & -.39 & .007 & & & - & - & & & - & - \\
\hline CVLT intrusions (free and cued) & & & .13 & .35 & & & .22 & .07 & & & -.04 & .74 \\
\hline DSDT nondistraction & & & - & - & & & -.17 & .14 & & & .22 & .07 \\
\hline DSDT distractability index & & & .20 & .10 & & & - & - & & & - & - \\
\hline SFRT rules & & & .05 & .72 & & & - & - & & & - & - \\
\hline SFRT goals & & & - & - & & & -.12 & .25 & & & - & - \\
\hline
\end{tabular}

$-=$ variable not entered into regression model. 
indexes of thought disorder to be relatively distinct constructs (Craig, 1973; Harrow et al., 1997; Silverstein et al., 1993; Sponheim et al., 2003) in the current study they were strongly associated with each other and had generally similar neurocognitive correlates. We identified a subset of neurocognitive and social cognitive variables that together accounted for a substantial amount of variance in these aspects of formal thought disorder. The total amount of variance accounted for could be increased by adding general verbal ability to prediction equations, but even then the neurocognitive variables contributed significant additional variance.

The relationships between our measures of thought disorder and sustained, focused attention, verbal learning, immediate auditory memory, distractibility, and intrusions are consistent with the idea that basic cognitive deficits in initial discrimination of relevant stimuli and encoding of relevant information into memory are part of the causal pathways leading to formal thought disorder (Maher, 1972). The strength of the relationships between cognitive impairment and concrete thinking found in this study parallels the results reported by Sponheim et al. (2003). Intellectual ability and measures of attentional control and memory explained $67 \%$ of the variance in concreteness in the current study and 59\% in the Sponheim et al. study. Our finding that impairment in immediate memory and attentional control were related to concreteness is consistent with Spitzer's et al. (1993) theory that the ability to abstract is dependent upon working memory capacity to hold and manipulate information. Our findings regarding list learning intrusions are also consistent with the hypothesis of Harrow et al. (1989) that bizarre-idiosyncratic thinking results, in part, from an inability to adequately monitor verbal output for errors. Our current results from the attentional tasks replicate Silverstein et al.'s (1993) finding that intellectual ability and complex attention were predictive of bizarre-idiosyncratic thinking and extend earlier work relating sustained and complex attention and working memory capacity to positive formal thought disorder assessed with the Thought Disorder Index (Holzman et al., 1986; Nuechterlein et al., 1986) and the TLC (Andreasen, 1986; Harvey et al., 1988; Serper et al., 1990).

Further, our findings that social feature recognition was associated with bizarre proverb responding is consistent with Harrow's hypothesis (Harrow et al., 1989) that difficulty accessing information about what is socially appropriate in a given situation contributes to bizarre speech. In the current results, knowledge of social features was also related to concreteness, suggesting that concrete responses also reflect an unawareness of what is expected by the format of the testing situation. Multiple regression analyses did not isolate a significant predictive contribution from social feature recognition that was independent of the neurocognitive predictors, at least using the SFRT as the social cognitive measure.

To shed light on previous, disparate results regarding the relationship of general cognitive ability versus more circumscribed cognitive deficits to formal thought disorder, we examined the predictive contribution of discrete neurocognitive impairments after controlling for global verbal ability with the WAIS-R Vocabulary subtest. However, this is a very conservative approach, as the specific neurocognitive deficits that contributed to thought disorder on the proverb test could also impair performance on the vocabulary test. For example, basic cognitive deficits that result in concrete thinking will, in turn, lead to incorrect descriptions of word definitions. Thus, vocabulary knowledge is likely to be an indicator of both premorbid verbal ability in these patients as well as neurocognitive deficits associated with psychosis, which would inflate the relationship between verbal ability and thought disorder. Even with this conservative method, a group of neurocognitive variables examined in this study were found to significantly contribute to the overall prediction of both bizarre and concrete thinking. It may be noteworthy that, after accounting for general cognitive ability, only verbal learning independently contributed to the prediction of bizarre and concrete responses.

The use of the Bizarre-Idiosyncratic Thinking Rating System and the Abstract/Concrete Rating System limits this study to only two dimensions of formal thought disorder. In contract, use of the TLC, which is rated based on responses during a clinical interview, would have allowed a more comprehensive assessment of thought disorder. However, the current participants had low BPRS conceptual disorganization item ratings, and would likely also have had low TLC ratings. Our set of cognitive predictors accounted for 
far less variance in thought disorder rated based on responses during a clinical interview (i.e., the BPRS conceptual disorganization item), than in bizarre proverb responses. Because the BPRS conceptual disorganization rating is less sensitive to subtle thought disorder than the proverbs measure, it was harder to predict that BPRS rating as it contains less true score variance. This finding is consistent with our previous work, wherein a brain region known to be associated with formal thought disorder was more strongly associated with bizarre proverb responses than with the BPRS conceptual disorganization item (Subotnik et al., 2003). Thus, these results are consistent with the view that speech elicited by the proverbs test and rated using the Bizarre-Idiosyncratic Rating System is a more sensitive indicator of formal thought disorder than is this BPRS item.

Our results are also consistent with Harrow et al.'s (2004) finding that the proverbs test, which involves a working memory component, more frequently elicited severe thought disorder than a task that did not involve working memory. It is possible that the neurocognitive measures in the current study share more overlapping variance with the proverbs responses than the BPRS conceptual disorganization item because the proverbs test is in itself a cognitive task.

Our regression analyses were completed to identify which discrete cognitive variables made independent contributions to the prediction of anomalous proverbs responding. These models took advantage of preselection of predictor variables already shown to be associated with the outcome measure in this sample. Thus, the resulting impressive amount of variance accounted for in the multiple regression models requires replication in a separate sample. Our use of the SFRT allowed us to include a brief measure of social cognition in this battery. However, the SFRT had a substantial ceiling effect, which required data transformation prior to analysis. Future studies should examine whether a wider range of social cognition measures, with better psychometric properties, are associated with formal thought disorder in a way that is independent of the role of basic neurocognitive measures. Another limitation of this study was that the sustained, focused attention measures were not available on all participants, thus precluding their use in the multiple regression analyses. Thus, the independent predictive contributions of these meas- ures could not be determined. Nevertheless, this study shows the promise of neurocognitive and social cognitive deficits as correlates and possible determinants of formal thought disorder in schizophrenia.

\section{Acknowledgements}

We would like to gratefully acknowledge the UCLA Aftercare Research Program patients who participated in the research. We also gratefully acknowledge consultation from Sun Hwang, MS, $\mathrm{MPH}$, of the Data and Methodology Core of the UCLA Center for Neurocognition and Emotion in Schizophrenia. We thank Praveen Raja, PhD, who helped in the collection and recording of the symptomatology and cognitive testing measures.

This research was supported in part by the National Institute of Mental Health Grants MH37705 (P.I.: Keith H. Nuechterlein, PhD), MH30911 (P.I.: Robert P. Liberman, M.D.), and MH66286 (P.I.: Keith H. Nuechterlein, $\mathrm{PhD}$ ).

\section{References}

Adler, D., Harrow, M., 1974. Idiosyncratic thinking and personally overinvolved thinking in schizophrenic patients during partial recovery. Comprehensive Psychiatry 15, 57-67.

American Psychiatric Association, 1994. Diagnostic and Statistical Manual of Mental Disorders (DSM-IV). American Psychiatric Press, Washington, DC.

Andreasen, N.C., 1986. Scale for the assessment of thought, language, and communication (TLC). Schizophrenia Bulletin $12,473-482$.

Andreasen, N.C., Olsen, S.A., 1982. Negative v positive schizophrenia: definition and validation. Archives of General Psychiatry $39,789-794$.

Asarnow, R.F., MacCrimmon, D.J., 1982. Attention/information processing, neuropsychological functioning, and thought disorder during the acute and partial recovery phases of schizophrenia: a longitudinal study. Psychiatry Research 7, 309-319.

Barrera, A., McKenna, P.J., Berrios, G.E., 2005. Formal thought disorder in schizophrenia: an executive or a semantic deficit? Psychological Medicine 35, 121-132.

Bleuler, E., 1950. Dementia Praecox or the Group of Schizophrenias. International Universities Press, New York, NY.

Bowie, C., et al., 2005. The longitudinal course of thought disorder in geriatric patients with chronic schizophrenia. American Journal of Psychiatry 162, 793-795.

Carpenter, B.N., Chapman, L.J., 1982. Premorbid status in schizophrenia and abstract, literal or autistic proverb interpretation. Journal of Abnormal Psychology 91, 151-156. 
Carter, M.L., 1986. The assessment of thought deficit in psychotic unipolar depression and chronic paranoid schizophrenia. Journal of Nervous and Mental Disease 174, 336-341.

Corrigan, P., Green, M., 1993. The Situational Feature Recognition Test: a measure of schema comprehension for schizophrenia. International Journal of Methods in Psychiatric Research 3, 29-35.

Corrigan, P.W., Wallace, C.J., Green, M.F., 1992. Deficits in social schemata in schizophrenia. Schizophrenia Research 8, $129-135$.

Craig, R.J., 1973. Interpersonal competition, overinclusive thinking, and schizophrenia. Journal of Consulting and Clinical Psychology $40,9-14$.

Delis, D.C., Kramer, J.H., Kaplan, E., Ober, B.A., 1983. California Verbal Learning Test, Research edition The Psychological Corporation, Cleveland, $\mathrm{OH}$.

Docherty, N.M., Gordinier, S.W., 1999. Immediate memory, attention, and communication disturbances in schizophrenia patients and their relatives. Psychological Medicine 29, $189-197$.

Docherty, N.M., Cohen, A.S., Nienow, T.M., Dinzeo, T.J., Dangelmaier, R.E., 2003. Stability of formal thought disorder and referential communication disturbances in schizophrenia. Journal of Abnormal Psychology 112, 469-475.

Gorham, D.R., 1956. A proverbs test for clinical and experimental use. Psychological Reports 2, 1-12.

Harrow, M., Adler, D., Hanf, E., 1974. Abstract and concrete thinking in schizophrenia during the prechronic phases. Archives of General Psychiatry 31, 27-33.

Harrow, M., Lanin-Kettering, I., Miller, J.G., 1989. Impaired perspective and thought pathology in schizophrenic and psychotic disorders. Schizophrenia Bulletin 15, 605-623.

Harrow, M., Sands, J.R., Silverstein, M.L., Goldberg, J.F., 1997. Course and outcome for schizophrenia versus other psychotic patients: a longitudinal study. Schizophrenia Bulletin 23, 287-303.

Harrow, M., Jobe, T.H., Herbener, E.S., Goldberg, J.F., Kaplan, K.J., 2004. Thought disorder in schizophrenia: working memory and impaired context. Journal of Nervous and Mental Disorders 192, 3-11

Harvey, P.D., Earle-Boyer, E.A., Levinson, J.C., 1988. Cognitive deficits and thought disorder: a retest study. Schizophrenia Bulletin 14, 57-66.

Harvey, P.D., et al., 1998. Symptoms, cognitive functioning, and adaptive skills in geriatric patients with lifelong schizophrenia: a comparison across treatment sites. American Journal of Psychiatry $155,1080-1086$.

Hertler, C.A., Chapman, L.J., Chapman, J.P., 1978. A scoring manual for literalness in proverb interpretation. Journal of Consulting and Clinical Psychology 46, 551-555.

Holzman, P.S., Shenton, M.E., Solovay, M.R., 1986. Quality of thought disorder in differential diagnosis. Schizophrenia Bulletin $12,360-371$.

Kerns, J.G., Berenbaum, H., 2002. Cognitive impairments associated with formal thought disorder in people with schizophrenia. Journal of Abnormal Psychology 111, 211-224.
Lezak, M.D., 1995. Neuropsychological Assessment. Oxford University Press, New York.

Liddle, P.F., 1987. The symptoms of chronic schizophrenia: a reexamination of the positive-negative dichotomy. British Journal of Psychiatry 151, 145-151.

Maher, B., 1972. The language of schizophrenia: a review and interpretation. British Journal of Psychiatry 120, 3-17.

Marengo, J.T., Harrow, M., Lanin-Kettering, I., Wilson, A., 1986. Evaluating bizarre-idiosyncratic thinking: a comprehensive index of positive thought disorder. Schizophrenia Bulletin 12, 497-511.

Moser, R.K., Cienfuegos, A., Barros, J., Javitt, D., 2001. Auditory distraction and thought disorder in chronic schizophrenic inpatients: evidence for separate contributions by incapacity and poor allocation and a subsyndrome related to the allocation deficit. Schizophrenia Research 51, 163-170.

Nestor, P.G., et al., 1998. Word recall in schizophrenia: a connectionist model. American Journal of Psychiatry 155, $1685-1690$.

Nuechterlein, K.H., 1983. Signal detection in vigilance tasks and behavioral attributes among offspring of schizophrenic mothers and among hyperactive children. Journal of Abnormal Psychology $92,4-28$.

Nuechterlein, K.H., Asarnow, R.F., 1999a. Degraded Stimulus Continuous Performance Test (DS-CPT) Program for IBMCompatible Microcomputers, Version 8.11. Authors, Los Angeles.

Nuechterlein, K.H., Asarnow, R.F., 1999b. Memory-Load Continuous Performance Test (3-7 CPT) Program for IBM-Compatible Microcomputers. Authors, Los Angeles.

Nuechterlein, K.H., Edell, W.S., Norris, M., Dawson, M.E., 1986. Attentional vulnerability indicators, thought disorder, and negative symptoms. Schizophrenia Bulletin 12, 408-426.

Nuechterlein, K.H., Dawson, M.E., Gitlin, M., Ventura, J., et al., 1992. Developmental processes in schizophrenic disorders: longitudinal studies of vulnerability and stress. Schizophrenia Bulletin 18, 387-425.

Oltmanns, T.F., 1978. Selective attention in schizophrenic and manic psychoses: the effect of distraction on information processing. Journal of Abnormal Psychology 87, 212-225.

Oltmanns, T.F., Neale, J.M., 1975. Schizophrenic performance when distractors are present: attentional deficit or differential task difficulty? Journal of Abnormal Psychology 84, 205-209.

Pandurangi, A.K., Sax, K.W., Pelonero, A.L., Goldberg, S.C., et al., 1994. Sustained attention and positive formal thought disorder in schizophrenia. Schizophrenia Research 13, 109-116.

Rosvold, H.E., Mirsky, A.F., Sarason, I., Bransome Jr., E.D., Beck, L.H., 1956. A continuous performance test of brain damage. Journal of Consulting Psychology 20, 343-350.

Serper, M.R., Bergman, R.L., Harvey, P.D., 1990. Medication may be required for the development of automatic information processing in schizophrenia. Psychiatry Research 32, 281-288.

Shimkunas, A.M., Gynther, M.D., Smith, K., 1966. Abstracting ability of schizophrenics before and during phenothiazine therapy. Archives of General Psychiatry 14, 79-83. 
Silverstein, M.L., Marengo, J.T., Fogg, L., 1991. Two types of thought disorder and lateralized neuropsychological dysfunction. Schizophrenia Bulletin 17, 679-687.

Silverstein, M.L., Harrow, M., Marengo, J.T., 1993. Disordered thinking and cerebral dysfunction: laterality effects, language, and intellectual functions. Archives of Clinical Neuropsychology $8,497-509$.

Sowell, E.R., et al., 2000. Abnormalities in early-onset schizophrenia spectrum disorder observed with statistical parametric mapping of structural magnetic resonance images. American Journal of Psychiatry 157, 1475-1484.

Spitzer, R.L., Endicott, J., Robins, E., 1978. Research diagnostic criteria: rationale and reliability. Archives of General Psychiatry $35,773-782$.

Spitzer, M., Braun, U., Maier, S., Hermle, L., et al., 1993. Indirect semantic priming in schizophrenic patients. Schizophrenia Research $11,71-80$.
Sponheim, S.R., Surerus-Johnson, C., Leskela, J., Dieperink, M.E., 2003. Proverb interpretation in schizophrenia: the significance of symptomatology and cognitive processes. Schizophrenia Research 65, 117-123.

Subotnik, K.L., Bartzokis, G., Green, M.F., Nuechterlein, K.H., 2003. Neuroanatomical correlates of formal thought disorder in schizophrenia. Cognitive Neuropsychiatry 8, 81-88.

Ventura, J., et al., 1993. Brief Psychiatric Rating Scale (BPRS) expanded version: scales, anchor points, and administration manual. International Journal of Methods in Psychiatric Research 3, 227-243.

Wechsler, D., 1981. WAIS-R Manual: Wechsler Adult Intelligence Scale-Revised. Psychological Corporation, San Antonio, TX. 